REVISTA ANDALUZA DE ANTROPOLOGÍA

NÚMERO 13:

SEPTIEMBRE DE 2017

ISSN 2174-6796

[pp. 25-52]

http://dx.doi.org/10.12795/RAA.2017.13.02

\title{
LAS PROCESIONES DE LOS OTROS. IDENTIDAD Y TERRITORIO EN LAS ROMERÍAS LATINOAMERICANAS DE SEVILLA
}

\section{THE PROCESSIONS OF THE OTHERS. IDENTITY AND TERRITORY IN THE LATIN AMERICAN RELIGIOUS FEASTS IN SEVILLE}

\section{Francisco José Cuberos Gallardo}

Centro de Investigação e Estudos de Sociologia - Instituto Universitário de Lisboa (CIES-IUL)

\section{Resumen}

Los inmigrantes latinoamericanos residentes en la ciudad de Sevilla celebran periódicamente romerías religiosas directamente importadas desde sus países de origen. La reproducción de estas fiestas en el contexto migratorio implica todo un proceso de apropiación, delimitación y definición de nuevos espacios. En este artículo hacemos uso del método etnográfico para acercarnos a los distintos modos de intervención sobre el espacio que estas romerías plantean en sus diferentes fases de desarrollo. Todos ellos son interpretados en tanto estrategias de re-territorialización de la identidad, que permiten a los inmigrantes negociar simultáneamente su derecho a mantener una identidad cultural diferenciada y su voluntad por participar de la ciudad en que viven. 


\title{
Palabras clave
}

Migración, Latinoamérica, Identidad, Territorio, Religiosidad, Integración

\begin{abstract}
The Latin American immigrants living in Seville periodically celebrate religious feasts imported from their home countries. The reproduction of these events in the migratory context implies a whole process of appropriation, delimitation and definition of new spaces. In this paper the ethnographic method is used to approach the different modes of intervention on the space which these feasts pose in their different stages of development. Such interventions are interpreted as strategies for a re-territorialization of identity, which allow immigrants to negotiate both their right to maintain a differentiated cultural identity and their willingness to participate in the city in which they live.
\end{abstract}

\section{Keywords}

Migration, Latin America, Identity, Territory, Religiosity, Integration

\section{INTRODUCCIÓN}

Los inmigrantes de origen latinoamericano suman casi la mitad de los aproximadamente cuarenta mil extranjeros que residen en la ciudad de Sevilla. Dentro de esta población destacan por su peso demográfico los bolivianos, colombianos y ecuatorianos, si bien existe también una representación notable de grupos como los peruanos, argentinos, paraguayos, chilenos, venezolanos y mexicanos. Dentro de estos colectivos se observa una tendencia recurrente a celebrar romerías que reproducen tradiciones propias de los distintos países de origen. Los peruanos llevan varios años festejando al Señor de los Milagros, mientras que los ecuatorianos hacen lo propio con la Virgen del Quinche, los bolivianos con la de Urkupiña, los mexicanos con la de Guadalupe y los paraguayos con la de Caacupé.

A través de estas celebraciones, los inmigrantes reafirman su identidad cultural y su voluntad de seguir formando parte de su comunidad desde la distancia. Sin embargo, el contexto migratorio impone sus propios condicionantes, y de hecho plantea un desafío radical a estas romerías, al romper el vínculo entre comunidad y territorio que está en la base de estas fiestas. En efecto, todas estas romerías han sido tradicionalmente celebradas, en los países de origen, dentro de lo que podemos considerar un régimen de territorialidad estable. Dentro de este modelo, los referentes espaciales de la fiesta permanecen fijos en el tiempo, incluyendo el propio santuario, que ocupa generalmente el lugar central de la fiesta y que funciona como el eje físico que permite la congregación 
periódica de los peregrinos. Es precisamente esta continuidad en el espacio la que hace posible la intermitencia en el tiempo: los peregrinos pueden dispersarse cada año porque tienen un lugar al que volver.

En el contexto migratorio, sin embargo, estas fiestas son reconstruidas en ausencia de los referentes espaciales que las sustentan. Así, y en el caso de los latinoamericanos residentes en Sevilla, observamos que cada nueva edición de una romería exige de los inmigrantes encontrar un parroquia disponible, contactar con un sacerdote dispuesto a oficiar una misa, conseguir un espacio en que celebrar la fiesta que sigue a la ceremonia religiosa y hacer llegar a la comunidad información precisa sobre la ubicación de estos espacios y sobre el recorrido de la procesión. La posición precaria de estas personas dentro de la sociedad receptora determina que el acceso a estos espacios tenga que ser renegociado cada año. Para cada fiesta los romeros necesitan dotarse de nuevos santuarios en torno a los cuales organizar la peregrinación. Podemos afirmar por tanto que, si en el país de origen la romería se sustenta en un régimen de territorialidad estable, en el contexto migratorio pasa a ser reconstruida dentro de un régimen territorial precario marcado por la contingencia de los referentes espaciales.

En el trabajo que se presenta abordamos, a través de la descripción etnográfica, este proceso de re-territorialización de las romerías latinoamericanas en Sevilla, apuntando tanto los obstáculos que los migrantes encuentran para reproducir su propia identidad en un nuevo territorio como las estrategias que desarrollan para dar respuesta a dichos obstáculos ${ }^{1}$. Nos interesa analizar las formas de vinculación entre comunidad y territorio que los inmigrantes latinoamericanos despliegan en Sevilla a través de sus romerías religiosas. Entendemos que esas formas de vinculación, complejas y heterogéneas, apuntan líneas de indagación interesantes en torno a una multiplicidad de problemáticas que son centrales en los procesos migratorios.

En primer lugar, la reconstrucción espacial de la fiesta permite a estas personas explorar los límites y contradicciones de sus niveles de integración en la ciudad. Las dificultades para acceder a determinados espacios que les son vetados, así como los subsiguientes procesos de negociación con diferentes agentes de la sociedad receptora -instituciones privadas, iglesias, ONGs, empresas privadas, etc.- tornan explícitas las fronteras que con frecuencia demarcan la exclusión de esta población de determinados lugares físicos y simbólicos de la ciudad, así como su participación precaria de otros espacios.

1. Deseo hacer constar mi agradecimiento a todas las personas que colaboraron durante la realización del trabajo de campo, y muy especialmente a las integrantes de las siguientes organizaciones: Asociación religiosa de devotos del Señor de los Milagros en Sevilla, Comisión organizadora de fiestas en honor a la Virgen de Caacupé en Sevilla, Grupo folklórico Mayenbe, Grupo Folklórico Mitimaes, Ballet Andalatino, Asociación de Ecuatorianos en Andalucía, Taller de Arte y Cultura Popular América Mestiza, Asociación Mexicanos en Andalucía, Asociación Amigos de Perú en Sevilla, Asociación Paraguayos sin Fronteras, Asociación Juventud Boliviana. 
En segundo lugar, la organización de la fiesta en la distancia entraña un ejercicio de re-articulación de los distintos elementos materiales y simbólicos que la componen, planteando inevitablemente una tensión entre la voluntad por reproducir fielmente los patrones originales de la romería y la necesidad de adaptar los mismos a la realidad diferenciada del contexto migratorio. Las romerías latinas expresan de manera condensada las negociaciones y contradicciones de unos colectivos humanos que, en su experiencia migratoria, se esfuerzan tanto por ser parte de la sociedad receptora como por conservar sus propias identidades diferenciadas.

Finalmente, el desarrollo material de las romerías permite a estas poblaciones migrantes visibilizar unos paisajes donde también se reserva un lugar a los definidos como otros. En este sentido, una romería ecuatoriana puede ofrecernos datos de interés sobre el nivel y los modos de participación que en ella se reserve a otros colectivos latinoamericanos, a la población autóctona de la ciudad o a vecinos inmigrantes de otras procedencias. Tanto los desiguales grados de presencia como las ausencias absolutas del espacio romero ofrecen una información interesante sobre la relación de cada grupo con la ciudad y sus vecinos.

La reflexión sobre estos diversos ejes constituye el objetivo central de este artículo. Para abordarlo optamos por un acercamiento etnográfico a las características generales de estas romerías, centrando nuestra atención en los usos que los protagonistas dan a distintos espacios en dichas fiestas. Así, en un primer apartado describimos las principales dificultades que estos inmigrantes encuentran para reconstruir sus romerías en la ciudad de Sevilla. Posteriormente nos detenemos en las prácticas de reterritorialización que estas fiestas canalizan, atendiendo tanto a los usos que los inmigrantes dan a diferentes espacios como a los condicionantes que el propio contexto espacial impone a estas romerías. Para esta tarea nos apoyamos en datos recabados a lo largo de cinco años de trabajo de campo etnográfico, distribuidos en dos grandes etapas: una primera, de carácter menos intrusivo, basada en una combinación de observación participante y entrevista y desarrollada entre 2008 y 2009; y una segunda, centrada en ejercicios prolongados de observación participante y análisis de red, prolongada entre 2010 y 2012. Todo este trabajo se enmarca dentro de una investigación presentada como tesis doctoral en 2012 con el título "Relaciones interétnicas y participación democrática. Estrategias asociativas de los inmigrantes latinoamericanos residentes en Sevilla”.

La importancia de estas romerías radica, según nuestra hipótesis de partida, en su potencialidad para dotar de visibilidad pública una pluralidad de identidades que, a su

2.Dichainvestigación fue realizada con el apoyo de una beca del Plan Nacional de Profesorado Universitario (FPU) del Ministerio de Educación español (Referencia AP2006-01515). Actualmente el autor continúa investigando las prácticas asociativas de los inmigrantes latinoamericanos en Sevilla dentro de un estudio comparado con el caso de los inmigrantes procedentes de las antiguas colonias portuguesas en la ciudad de Lisboa. Esta última investigación cuenta con el apoyo de una beca postdoctoral de la Fundação para a Ciência e a Tecnologia (FCT) de Portugal (SFRH/BPD/85438/2012). 
vez, son así negociadas en tanto parte legítima de la sociedad receptora. La descripción etnográfica apunta por tanto a las formas en que los distintos grupos se construyen y hacen visibles a través de las romerías, y a los procesos de negociación asociados a este empeño. Para una correcta interpretación de los datos recogidos, reflexionamos previamente sobre el encaje de estas romerías en el debate teórico sobre la articulación entre migración, identidad y territorio.

\section{ROMERÍAS MIGRANTES: RE-ARTICULANDO IDENTIDADES EN UN RÉGIMEN TERRITORIAL PRECARIO}

Las romerías constituyen importantes expresiones de religiosidad popular, que movilizan periódicamente la participación activa de millones de personas en pleno siglo XXI. La fuerte implantación de estas fiestas en la actualidad parecería contradecir las predicciones de aquellos autores que vieron en la Modernidad un imparable proceso de desencantamiento del mundo (Weber, 1988) y que aventuraron la desaparición progresiva de las prácticas religiosas de la vida pública. En zonas como el subcontinente latinoamericano el acelerado proceso de urbanización y las profundas transformaciones económicas de los últimos dos siglos no sólo no han acabado con estas formas de religiosidad, sino que de hecho observamos en la actualidad un repunte de su popularidad. Esta aparente paradoja, sin embargo, puede ser explicada si pasamos a interpretar las romerías desde el prisma teórico de las identidades colectivas. Desde esta perspectiva, proponemos que la renovada vitalidad de estas fiestas responde fundamentalmente a su eficacia para el refuerzo de identidades culturales específicas, que permiten a quienes participan de ellas reconocerse y ser reconocidos por los demás.

Las romerías habilitan la activación de símbolos que, por su identificación directa con un grupo, permiten visibilizar los límites entre sus miembros y "los otros", y afirmar así su especificidad (Barth, 1976). La participación de la romería no sólo hace posible afirmar las creencias particulares de cada romero, sino también, y sobre todo, su pertenencia a un "nosotros" específico y diferenciado. En este sentido, los símbolos centrales de la romería -generalmente un Cristo, un santo o una Virgen- absorben durante la fiesta unos significados que exceden el terreno de la religión para convertirse en marcadores de la identidad de un grupo (Moreno, 1990).

La visibilización física de ese "nosotros" sólo llega a materializarse mediante la aplicación de una serie de intervenciones sobre el territorio en que se enmarca la romería. Así, cabe destacar en primer lugar la apropiación temporal que el grupo hace del territorio, que durante unas horas o unos días es poblado por personas que no lo frecuentan durante el resto del año. Estas personas dan además usos diferenciados a los elementos del paisaje, que contrastan claramente con los usos que reciben cotidianamente -por ejemplo, cuando se duerme en el campo, cuando se canta frente a una fuente del camino 
o cuando se bautiza a los nuevos romeros en un río- ${ }^{3}$. Incluso el propio transporte de la imagen sagrada produce a menudo una unidad territorial que aglutina paisajes muy diversos y que sólo tienen un sentido unitario para los propios romeros, de tal forma que cualquiera que no lo sea puede transitar el territorio sin percatarse de su especial significación religiosa. Todo este conjunto de intervenciones y de formas diferenciadas de apropiación del espacio responden, en definitiva, a un proceso de territorialización, y apunta por tanto a la dimensión cultural del espacio.

En este trabajo nos apoyamos en el concepto de territorialización para analizar las formas específicas en que los inmigrantes latinoamericanos producen su propio espacio en la ciudad de Sevilla a través de sus romerías. Esta producción del espacio propio -con un sentido específico para el grupo- ha sido definida por Garcés (2006: 6) en los términos de un proceso de configuración espacial, que entraña necesariamente el establecimiento de formas diferenciadas de apropiación, delimitación y/o definición funcional del espacio. Así, nos interesará describir de manera detallada las estrategias que habilitan a los inmigrantes para acceder a espacios concretos, pero también las limitaciones que encuentran y los modos concretos de intervención que les permiten dotar a esos espacios de nuevos significados.

El hecho de tratar con inmigrantes introduce una clara singularidad en el caso estudiado. El territorio sobre el que estas personas intervienen no es el de su sociedad de origen, ni el espacio físico en que tradicionalmente han sido celebradas sus romerías: por el contrario, tratamos con un espacio que en principio es ajeno a estos inmigrantes y del cual participan precariamente. En consecuencia, hablamos en términos estrictos de un proceso de re-territorialización, esto es: de una reconstrucción de las prácticas romeras en un contexto distinto al que originalmente les sirve de referencia.

La importación de romerías a las sociedades receptoras es una pauta habitual entre las poblaciones migrantes de origen latinoamericano, que ha sido constatada tanto dentro del subcontinente (Barelli, 2014) como en Europa (Merino, 2003; Ares, 2011) y Estados Unidos (Odgers, 2008). Estas prácticas de reterritorialización responden a la necesidad de los inmigrantes de seguir siendo nosotros, pero simultáneamente han de ser negociadas ante la evidencia de vivir en una sociedad diferente y donde los miembros del grupo son minoría. Esto se aprecia claramente en la organización formal de las romerías, que de un lado evocan la fiesta que quedó en el país de origen y de otro se adaptan necesariamente a los condicionantes del contexto de recepción. En estas circunstancias entendemos que, además de encontrarse afectadas por la participación precaria de la sociedad receptora, las formas concretas de apropiación, delimitación y definición del espacio son el resultado

3. De Certeau (1984:100) aborda estos usos específicos como "relatos" que singularizan la experiencia del espacio de cada grupo. Estos relatos se separan de los usos previstos por arquitectos y urbanistas que, al igual que la gramática, se ubican en el nivel normativo y no son usos observables en la vida real. 
de un complejo proceso de negociación entre las tendencias antitéticas de fidelidad a la tradición y adaptación al nuevo contexto.

Esta tensión entre tradición y adaptación se encuentra inscrita en el núcleo mismo del concepto de identidad, tal y como nos recuerda Gilroy (1994) cuando afirma que la identidad ha de ser interpretada, más que como una repetición incesante, como "lo mismo que cambia". Así, las romerías latinas de Sevilla son la expresión de unas identidades que, en su propósito de seguir existiendo, mutan y se adaptan en sus formas de expresión. El contexto migratorio impone la progresiva cristalización de nuevos marcadores identitarios que pasan a integrar los paisajes romeros de los latinoamericanos en Sevilla. Las vírgenes del Quinche y Urkupiña, el Señor de los Milagros y nuestra señora de Caacupé se van incorporando a nuevos imaginarios poblados por locutorios, discotecas latinas, emisoras cumbiamberas y canchas de fútbol y ecua-voley. Es dentro de este paisaje migrante que las romerías ven su importancia renovada y su sentido actualizado. Tal y como Sassone (2007) demostrase para el caso de los bolivianos en Argentina, las prácticas de religiosidad popular -incluyendo las romerías- se revelan como una herramienta central en las estrategias de los inmigrantes para la construcción de lugares propios.

La necesidad de dotarse de esos lugares propios en los que visibilizar identidades diferenciadas no es exclusiva de las poblaciones migrantes, y de hecho es compartida por todos los grupos humanos conocidos. Ahora bien, en el caso de dichas poblaciones, la satisfacción de tal necesidad se ve constreñida por la posición de subalternidad estructural que ocupan en la red de relaciones que constituye la ciudad. Es necesario por tanto reconocer que, lejos de ser neutral, el espacio urbano aparece como un producto social que refleja y reproduce las desigualdades que atraviesan la sociedad (Lefebvre, 1991; Castells, 1977; Harvey, 1973; Lojkine, 1981), y que estas desigualdades determinan con frecuencia una especial dificultad para los migrantes a la hora de acceder a la ciudad y dotar así a sus identidades de visibilidad material. En contraste con la alta capacidad que las elites demuestran en la actualidad para someter el espacio urbano a sus propias estrategias, los migrantes, en tanto grupo minorizado, enfrentan una pluralidad de obstáculos de tipo legal, político y económico que condicionan de manera decisiva la plasmación espacial de sus intereses y de sus identidades (Winchester, Kong and Dunn, 2003). Sin embargo, el espacio urbano no puede ser entendido exclusivamente como un escenario de constricción y colonización por el poder. La apropiación y definición de ese mismo espacio urbano constituye paralelamente un eje estratégico de resistencia por parte de los sectores dominados (Kong and Yeoh, 2003: 13), entre los que inequívocamente se encuadran los migrantes que hoy viven en la ciudad de Sevilla. El uso de estos espacios para la organización de actividades propias, especialmente cuando éstas permiten afirmar de manera expresa una especificidad cultural, debe ser interpretado como un recurso 
estratégico de las poblaciones migrantes tanto para la conservación de identidades diferenciadas como para la negociación de su encaje en la ciudad.

De hecho, la organización de eventos religiosos ha sido una práctica recurrente en las estrategias de resistencia identitaria desarrolladas por múltiples grupos de posición subalterna. Emma Martín, por ejemplo, reflejó en su trabajo sobre los emigrantes andaluces en Cataluña la importancia central de las procesiones en tanto forma de visibilizar en el espacio público la presencia y la identidad diferenciada de esta población (Martín, 1992). En el marco de la propia ciudad de Sevilla, el fuerte arraigo y reconocimiento social que las procesiones y romerías ostentan entre el conjunto de la población han supuesto probablemente una especial motivación para diferentes minorías étnicas, que a lo largo de la historia han apostado por estas fórmulas a la hora de afirmar su singularidad cultural en unos códigos compartidos por el conjunto de los vecinos de la ciudad. Así, Isidoro Moreno $(1974 ; 1997)$ ha documentado cómo en diferentes momentos históricos grupos minoritarios como los negros, mulatos o gitanos han apostado por organizar sus propias procesiones como un modo de afirmar públicamente su presencia en la capital andaluza. Las romerías que hoy celebran los latinoamericanos no parecen ser ajenas a esta lógica, y demuestran una alta funcionalidad a la hora de visibilizar a los grupos que los practican dentro de unos códigos conocidos y mayoritariamente aceptados por la población autóctona.

A continuación describimos el caso de las romerías latinas de Sevilla y reflexionamos sobre el sentido de este fenómeno en el marco de la experiencia migratoria. Para ello, partimos de su contextualización dentro de un régimen espacial precario, marcado por la subalternidad estructural que afecta a estos inmigrantes.

\section{LA INCORPORACIÓN DE LA INMIGRACIÓN LATINOAMERICANA A LA CIUDAD DE SEVILLA}

Para entender la forma en que los migrantes reconstruyen sus romerías en Sevilla hemos de interpretar éstas dentro del régimen espacio-temporal en que operan (Martín et al., 2008; Pujadas, 1990; Torres, 2006). Para el caso concreto de esta ciudad se observa que, tal y como es frecuente en contextos migratorios, la incorporación de estas personas a la sociedad local tiene lugar en condiciones de subalternidad estructural. Ello se refleja especialmente en situaciones recurrentes de irregularidad administrativa entre los migrantes y en la inserción generalizada de estas personas en mercados de trabajo secundarios (Capel, 2002). Estos factores determinan una participación precaria de la sociedad receptora, que impone unas limitaciones evidentes a las estrategias de reproducción cultural de estos grupos.

La presencia de inmigrantes latinoamericanos en Sevilla se torna especialmente significativa a partir de 1998-1999, coincidiendo con la agudización de la situación 
política y financiera de Ecuador y Colombia, cuyos nacionales pasarán a constituir los principales colectivos inmigrantes de la ciudad en apenas cinco años. En paralelo se produce un crecimiento sostenido de la población peruana, que ya había comenzado a llegar a principios de la década de los noventa. Posteriormente, y a partir de 2002-2003, se observa un crecimiento acentuado de la población boliviana -actualmente el colectivo latinoamericano más numeroso en la ciudad, junto a ecuatorianos y colombianos- así como de los paraguayos, brasileños, venezolanos y argentinos (Martín et al., 2012). Así, en el año 2010 la población de origen extranjero residente en Sevilla llegará a sumar algo más de 47.000 personas, representando aproximadamente el 6,74\% del total de 704.198 habitantes en la ciudad (Datos del Padrón Municipal de Habitantes). Dentro de este conjunto, destaca por su importancia numérica la inmigración de origen latinoamericano, que suma a 21.951 personas, representando el $46,60 \%$ de la población inmigrante y el 3,12\% de la población total. A su vez, dentro de este colectivo destacan por su peso poblacional los nacionales de Bolivia, Colombia y Ecuador, con valores que oscilan entre las 2.500 y las 3.700 personas por cada grupo durante el período estudiado, siendo igualmente destacable la presencia de peruanos y argentinos. Por lo demás, esta población decrecerá durante el período 2010-2015, coincidiendo con la agudización de la crisis económica y por efecto de la migración de retorno y de la re-emigración hacia terceros destinos.

A la hora de instalarse en la ciudad, todos estos colectivos se benefician de ciertas ventajas legales, y muy especialmente de la posibilidad de entrar en territorio español como turistas sin necesidad de visado. Esta fórmula de entrada, la más frecuente, implica atravesar una primera etapa de irregularidad derivada de la caducidad de su permiso de estancia como turistas antes de la consecución de un permiso de trabajo y residencia. Con el tiempo, la mayoría logra regularizar su situación, y acceder a la nacionalidad española tras registrar dos años de residencia legal. Sin embargo, la precariedad administrativa de esta población se verá prolongada por efecto de la crisis económica que da inicio en 2008, y que afectará negativamente a miles de inmigrantes latinoamericanos aún sujetos a la necesidad de conservar un empleo estable para renovar su permiso de trabajo y residencia. A causa del creciente desempleo, es común que estas personas se encuentren incapacitadas para renovar sus permisos y caigan de manera recurrente en situaciones de "irregularidad sobrevenida" (Jarrín, Rodríguez y De Lucas, 2012). Actualmente el impacto de la irregularidad administrativa es desigual entre los distintos colectivos nacionales, estando más extendida entre aquellos colectivos de más reciente presencia en Sevilla (bolivianos y paraguayos).

Estas personas van a incorporarse mayoritariamente a un mercado de trabajo que podemos clasificar como "secundario" en los términos definidos por Piore $(1979 ; 1983)$. Ocupan por tanto puestos de trabajo caracterizados por la predominancia de bajos 
salarios, un alto grado de informalidad en la contratación y una práctica sistemática de la segmentación étnica (Massey et al., 1993; 1998), cuyo resultado es la conformación de sectores laborales diferenciados que son ocupados por trabajadores inmigrantes especialmente vulnerables en sus derechos. Esta precariedad laboral, junto con la precariedad administrativa descrita más arriba, son factores esenciales para entender el acceso limitado de estas personas al espacio físico de la ciudad. En primer lugar, los inmigrantes latinoamericanos van a encontrar serias dificultades para acceder al espacio residencial. La obtención de una vivienda, ya sea en régimen de compra o alquiler, ha resultado muy difícil para esta población por coincidir en el tiempo su llegada a la ciudad con un contexto económico de hiperinflación del precio del suelo ligado a la especulación inmobiliaria (Arbaci, 2008). E igualmente van a tener dificultades para acceder a los espacios públicos de la ciudad, por disponer de escasos recursos económicos y por concentrarse mayoritariamente en barrios periféricos y con insuficiente infraestructura.

Esta breve contextualización nos permite entender las peculiares circunstancias en que los inmigrantes intentan rearticular sus identidades culturales en Sevilla. A la hora de reconstruir sus romerías tradicionales, observamos que estas personas carecen del tiempo, el espacio y los recursos que permitían su organización en las sociedades de origen. La escasez de tiempo libre, la dificultad para acceder a los espacios públicos y la necesidad de negociar las formas de co-presencia en ellos con la población autóctona imponen restricciones evidentes a la forma de desarrollar estas fiestas. Sin embargo, incluso en este contexto de precariedad se observa un fuerte empeño en esta población por recuperar sus romerías y continuar organizándolas en Sevilla. Sacar al Cristo o a la Virgen continúa siendo importante para una parte considerable de la población de origen latinoamericano residente en Sevilla, que demuestra un alto grado de coordinación y de entrega a la hora de reconstruir la fiesta cada año.

\section{SER ROMERO EN EL EXTRANJERO: RECONSTRUYENDO LA TRADICIÓN EN UN CONTEXTO DE PRECARIEDAD}

Cuando los inmigrantes reconstruyen sus fiestas tradicionales en el contexto migratorio visibilizan su propia presencia en la ciudad, lo cual entraña necesariamente una negociación con la población autóctona de esas formas de visibilidad. Debe notarse en este punto que, para el caso de las romerías latinoamericanas, Sevilla representa un escenario de singulares características. En una ciudad profundamente vinculada a festividades católicas en forma de procesión -Semana Santa, romería del Rocío, Virgen de los Reyes, Corpus Christi-, el transporte de imágenes religiosas por la vía pública es una práctica absolutamente normalizada, que en principio no despierta rechazo entre la población autóctona. Así, los propios inmigrantes latinoamericanos reconocen que, precisamente por la peculiar idiosincrasia de esta ciudad, las romerías constituyen una forma particularmente ventajosa de visibilizar su identidad cultural en formas atractivas 
para la población autóctona. En este sentido, y por contraste con otros colectivos inmigrantes como los magrebíes y subsaharianos, las romerías latinas revisten un carácter ambivalente, que de un lado afirman la especificidad cultural de los inmigrantes latinoamericanos y de otro su "compatibilidad" con la población autóctona ${ }^{4}$.

En todo caso, la organización de estas romerías entraña dificultades prácticas directamente derivadas del hecho de estar en tierra extraña. Un primer reto en este sentido es proveer a la fiesta de su símbolo central: la imagen a venerar. En todos los colectivos nacionales se observa que son generalmente grupos de mujeres los que impulsan el proyecto de rescate de la romería, al menos en sus primeras fases, y por tanto también la búsqueda de la imagen. Esta marcada tendencia a la feminización parece conectar en ocasiones con el protagonismo de las mujeres en algunas de estas procesiones en su tierra de origen. Sin embargo, es importante notar que las migraciones latinoamericanas a España presentan como uno de sus rasgos distintivos una fuerte feminización, especialmente notable en los grupos más numerosos -bolivianos, ecuatorianos, colombianos- y durante las etapas tempranas de la migración, por lo que este renovado protagonismo femenino en la organización de las fiestas también entronca con el propio peso de las mujeres en los flujos migratorios implicados. Estos grupos de mujeres suelen operar, al menos durante el primer año, como una proto-hermandad que comienza siempre por intentar "traer" al Cristo o a la Virgen desde el país de origen. Este desplazamiento geográfico de la imagen sagrada puede asumir distintas formas. La opción preferida suele ser importar desde el país de origen una imagen que es así considerada "original". Así lo hicieron los paraguayos, cuando el padre de una de las mujeres impulsoras de la romería envió por mensajería una estatuilla desde la ciudad de Asunción. Otras veces no es posible importar la imagen completa desde el país de origen. Se puede optar entonces por encargar en Sevilla la construcción de una imagen tallada de características lo más similares posibles a la original, y posteriormente la importación desde el país de origen de algún accesorio -un manto, una túnica, un lazo- que es añadido a la nueva imagen y que ostenta un valor especialmente emotivo por funcionar como garante de la originalidad y elemento conector con la tradición. Para sufragar estos gastos, las hermandades y proto-hermandades tratan de recabar fondos a través de diferentes iniciativas. Entre los colectivos más numerosos y más organizados, como los ecuatorianos y peruanos, se elige a uno o varios mayordomos ${ }^{5}$ que asumen una especial responsabilidad en la tarea de financiación de la fiesta, ya sea buscando con especial ahínco los recursos necesarios o aportándolos personalmente. Sin embargo, es muy común que ni siquiera los mayordomos consigan cubrir todos los

4. Para una discusión en profundidad de los discursos sobre la supuesta compatibilidad cultural de la inmigración latinoamericana en España, véase Martín et al. 2012.

5. El mayordomo es un cargo formalmente reconocido, elegido específicamente para cada edición de la romería, y que tiene como funciones principales tanto cuidar el correcto desarrollo de la fiesta como atender los gastos derivados de su celebración. 
costes que implican la construcción y decoración de una imagen tallada. Cuando esto sucede, se opta por métodos alternativos, como sustituir la imagen tallada por un cartel o fotografía de la imagen que es portada a modo de estandarte, tal y como han hecho durante años los organizadores de la romería peruana del Señor de los Milagros.

Una segunda dificultad es la de dotar a la fiesta de sus espacios de referencia. En ausencia del santuario original, los romeros han de procurarse una iglesia donde oficiar la ceremonia religiosa y un espacio amplio donde celebrar posteriormente una fiesta que incluye sistemáticamente el consumo de comida y bebida, así como el baile y la música. A diferencia de la imagen, que una vez adquirida puede ser usada en varias ocasiones, la dotación de espacios para la fiesta puede llegar a ser una preocupación permanente, ya que generalmente cada año reaparece la necesidad de encontrar una iglesia que acoja la misa y un local que albergue la fiesta posterior.

La tarea de encontrar una iglesia donde celebrar la ceremonia religiosa recae sobre los mayordomos y ayudantes, que intentan dotar a esta parte de la fiesta de una apariencia lo más próxima posible a la romería original. Así, es común que se contacte para esta tarea a sacerdotes que han sido misioneros en los países de origen, y que por ese motivo poseen un conocimiento directo de la fiesta y -supuestamente- una mayor sensibilidad hacia su valor. Cuando se consigue involucrar a un sacerdote de estas características, la misa es oficiada en la parroquia a la que dicho sacerdote está adscrito. Cuando no se encuentra un religioso de este perfil, los promotores de la romería intentan organizar la misa en alguna parroquia de los vecindarios con mayor población inmigrante, para favorecer el acceso a los potenciales interesados en participar de esta tradición. En todo caso la localización de una iglesia disponible no es tarea fácil, y es frecuente que una misma romería celebre su misa en una parroquia diferente cada año. En este sentido el santuario, cuya ubicación es estable en el modelo de romería tradicional, es aquí reubicado periódicamente en función de las circunstancias. Sólo los paraguayos parecen haber logrado el compromiso de una parroquia sevillana para alojar permanentemente su imagen, mientras otros grupos se enfrentan periódicamente a la necesidad de cambiar la ubicación de la misa central.

Una vez finalizada la ceremonia religiosa, la romería se prolonga durante toda la jornada dentro de un formato festivo en el que predomina la música y el baile, así como el consumo abundante de comidas y bebidas típicas del país de origen. Esta segunda parte de la fiesta es sin duda la más concurrida, y su desarrollo exige la obtención de un espacio amplio en el que poder concentrar a un alto número de personas, que puede alcanzar varios cientos de individuos. Hasta la fecha hemos observado tres estrategias básicas de acceso a estos espacios. Una primera consiste en solicitar a las autoridades locales la cesión de un espacio público en que reunirse, tal y como hicieron los peruanos en las primeras ediciones del Señor de los Milagros o los paraguayos para alojar la fiesta de la Virgen de 
Caacupé. Esta fórmula es la menos apetecible para los inmigrantes, por cuanto el disfrute de estos espacios suele encontrarse muy condicionado por la normativa municipal sus usos y horarios. En general, se intenta siempre la cesión de un espacio por parte de algún particular simpatizante de la romería, sea éste inmigrante o no. Así, los ecuatorianos han podido disfrutar durante varios años de una pequeña finca rural que ha sido prestada por un amigo de los organizadores y que les ha permitido recrear un ambiente cómodo y tranquilo. Finalmente, una tercera opción es cerrar un acuerdo con alguna de las llamadas discotecas latinas, locales de baile gestionados por latinoamericanos y ubicados en los polígonos industriales de las afueras de la ciudad (Cuberos, 2014). En este caso suele alcanzarse un acuerdo, por el que el titular del negocio cede el espacio a cambio de poder comerciar una parte de los productos consumibles, generalmente las bebidas.

Tanto si se pide a las autoridades como si se obtiene prestado de un particular, el local de la fiesta suele estar ubicado en lugares alejados del centro urbano de la ciudad. Esto marca un claro contraste entre la primera parte de la romería -la ceremonia religiosa- y la segunda -la fiesta-. Mientras que para la primera se busca preferentemente parroquias centrales que visibilicen la romería ante el conjunto de la ciudad, para la segunda se opta por sitios alejados que garanticen el protagonismo exclusivo de los inmigrantes. La primera parte tiene un carácter más público y abierto a la población autóctona, mientras que en la segunda se afirma de un modo más expreso el perfil latinoamericano de estas romerías.

\section{NUEVOS ESPACIOS PARA LAS VIEJAS TRADICIONES: PROCESOS DE APROPIACIÓN, DELIMITACIÓN Y DEFINICIÓN DEL TERRITORIO ROMERO}

Cada romería se celebra en coincidencia con la onomástica del Cristo o la Virgen homenajeada. No obstante, es común que la fiesta se traslade al sábado o domingo más cercano a dicha fecha, para así facilitar la asistencia a los interesados. En muchos casos, este día de fiesta va precedido por una novena, o un conjunto acotado de misas que permite a los fieles venerar por anticipado a su Cristo o a su Virgen, pero también aglutinar a los fieles y así agilizar los preparativos de la romería propiamente dicha. Esta fiesta central también es precedida con frecuencia por eventos seculares, como festivales y encuentros gastronómicos, que sirven igualmente como llamamiento a la comunidad y como medio de recaudación de recursos económicos.

El día de la romería, la ceremonia religiosa y la fiesta-convivencia marcan dos de las tres fases que componen la fiesta en su conjunto. Entre ellas se ubica la tercera, que consiste en el traslado físico de la imagen sagrada. Ésta es llevada en procesión por los romeros, preferentemente desde la puerta de la iglesia hasta el recinto de la fiesta. Cuando la distancia entre estos dos puntos es excesiva y hace imposible el traslado a pie, la imagen es transportada de un punto a otro en vehículo privado, si bien tanto en la salida de la iglesia como en la entrada al recinto festivo es cargada a pie por los romeros, evocando estéticamente los rasgos característicos de la romería original (cantos, música, etc.). 
En cada una de estas tres fases observamos modos diferenciados de apropiación, delimitación y significación del territorio. A continuación nos detenemos en cada una de ellas, analizando tanto sus características propias como su encaje en el conjunto de la romería.

\subsection{La ceremonia religiosa}

La romería comienza siempre con la celebración de una misa en honor a la Virgen o al Cristo correspondiente. A diferencia de algunas de las romerías originales latinoamericanas, donde existe una peregrinación previa a la ceremonia religiosa, en Sevilla es esta última la que marca el inicio de la celebración. La misa central coincide generalmente con el horario acostumbrado de eucaristía de la parroquia correspondiente. Sin embargo, estas misas asumen un carácter claramente diferenciado que se hace evidente, en primer lugar, en el perfil de los asistentes: si bien no es ésta la fase más concurrida de la fiesta, los inmigrantes suelen asistir en número suficiente como para llenar la parroquia, escenificando así una ocupación física del espacio que expresa abiertamente su apropiación simbólica durante este breve ritual. Además, durante esta misa se reserva un lugar destacado, generalmente ante el altar, a la exposición pública de la imagen sagrada, que de esta forma preside la ceremonia.

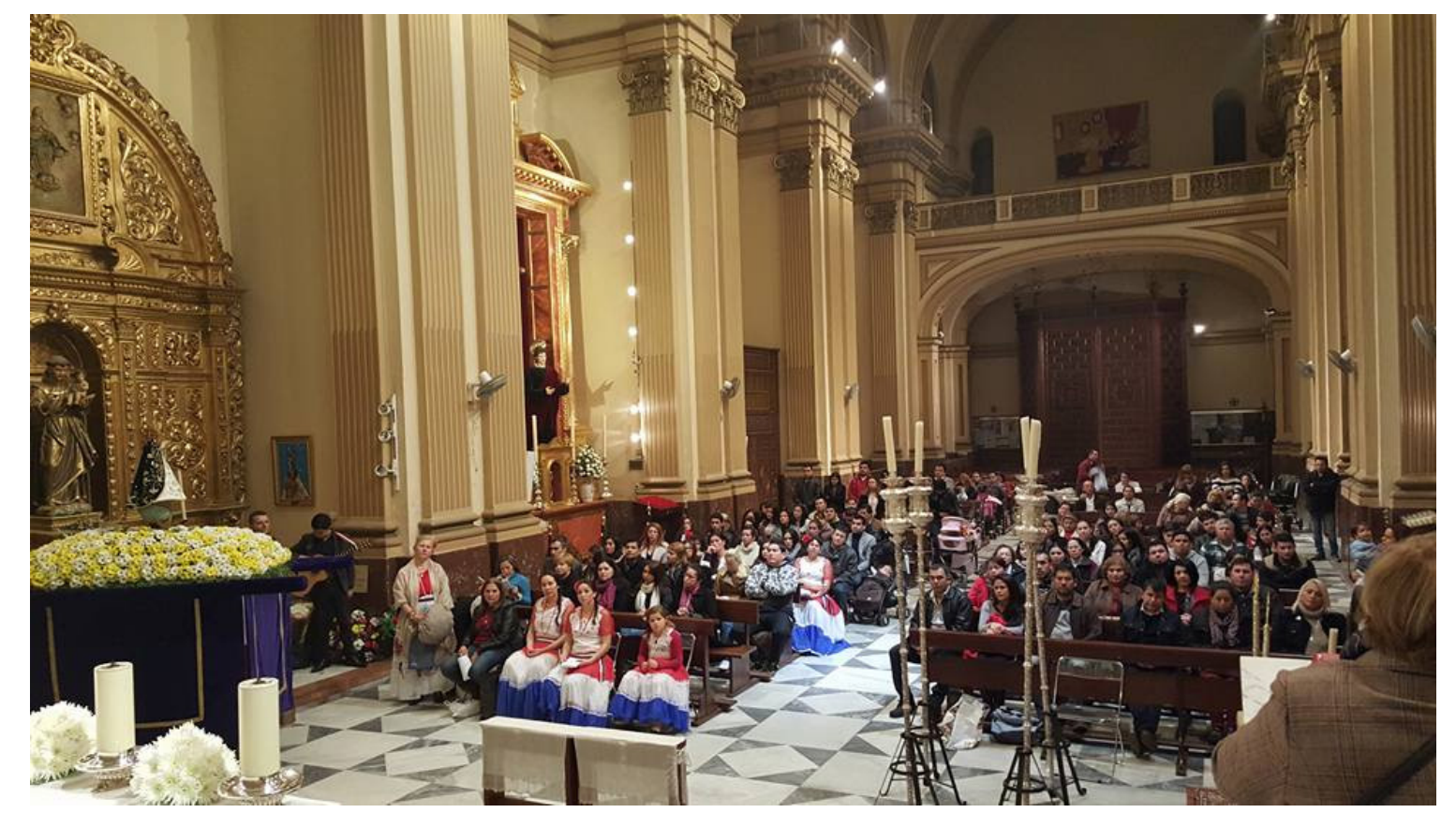

Imagen 1. Misa central en honor a la Virgen de Caacupé(Paraguay). Fuente: Comisión organizadora Fiestas en honor a la Virgen de Caacupé en Sevilla

La duración de la misa suele extenderse a menudo por más de una hora, siendo sensiblemente más larga que una misa ordinaria y debiendo esta mayor longitud a la incorporación a la ceremonia de elementos característicos de cada romería en cuestión. 
Así, los mayordomos negocian de antemano con el sacerdote la inclusión antes, durante y después de la eucaristía de intervenciones que demarcan la especificidad de la ocasión. El sacerdote reservará distintos momentos de la misa para la intervención de los inmigrantes, representados a través de sus mayordomos, que leerán oraciones, peticiones y bendiciones dirigidas específicamente a la figura homenajeada. También es común que en diferentes momentos de la ceremonia intervengan coros -por lo general compuestos de mujeres de avanzada edad- que interpretan cantos directamente ligados a la tradición de la fiesta o del país de origen.

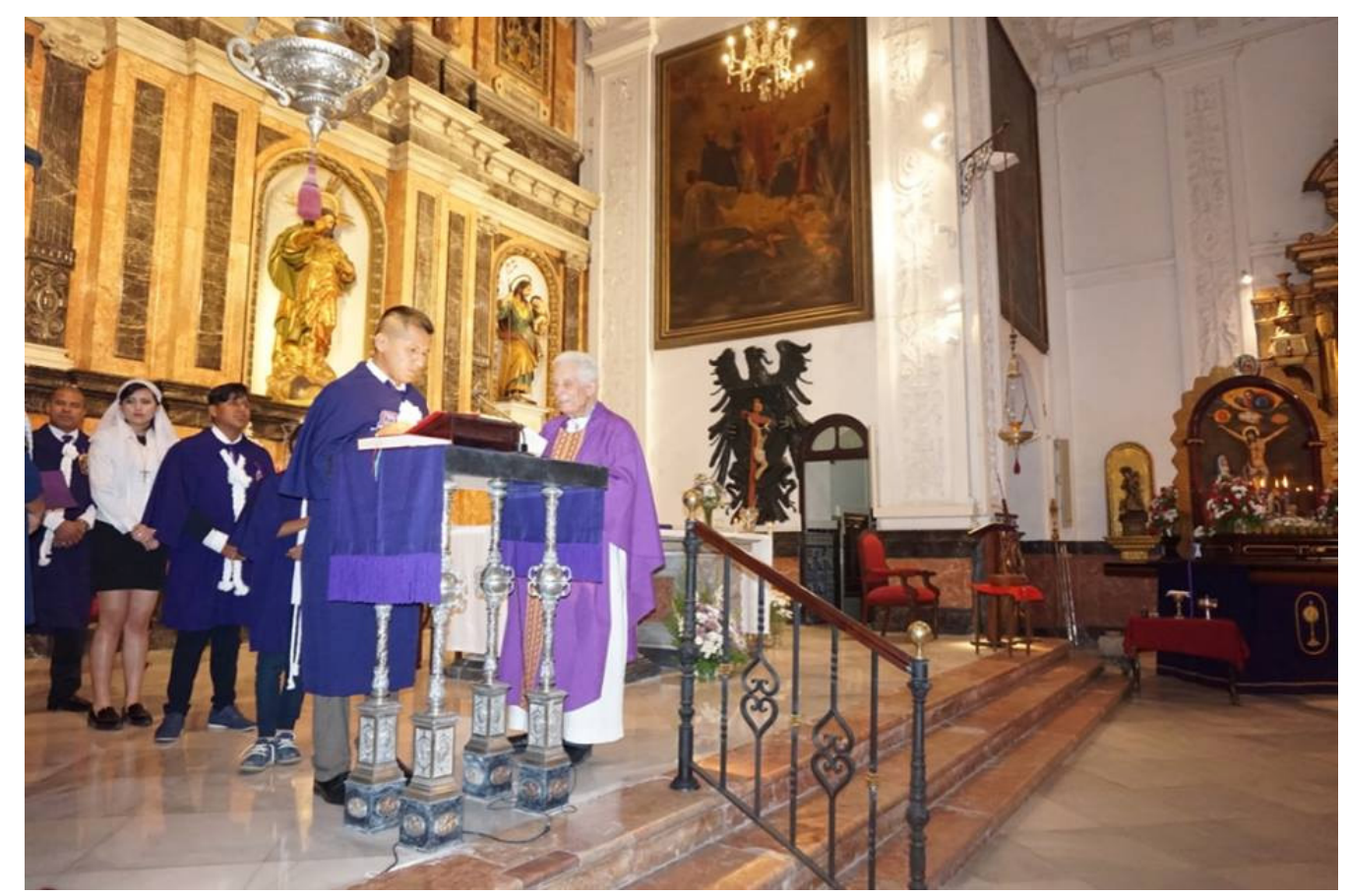

\section{Imagen 2. Representantes de la colectividad peruana durante la exposición de peticiones al Señor de los Milagros}

\section{Fuente: Asociación religiosa de devotos del Señor de los Milagros en Sevilla}

En esta primera fase de la romería se observa un reparto muy desigual del protagonismo dentro de los propios inmigrantes, que se refleja claramente en su disposición espacial dentro de la iglesia. Los primeros bancos son ocupados en exclusiva por los mayordomos y sus personas allegadas, que visibilizan así su especial compromiso con la fiesta y el trabajo desarrollado para su celebración. Aunque suele haber mayordomos de ambos sexos, el grupo promotor de la fiesta tiende a estar conformado por mujeres en mayor medida. Éstas asumen además un papel muy activo durante la misa, llevando la iniciativa en los cantos y oraciones, así como desarrollando acciones simbólicas en exclusiva -por ejemplo, la ofrenda de flores a la imagen sagrada- $y$ visibilizando su protagonismo antes y después de la eucaristía. 
Imágenes 3 y 4. Directiva de la Asociación religiosa de devotos del Señor de los Milagros en Sevilla durante y después de la eucaristía.

Fuente: Asociación religiosa de devotos del Señor de los Milagros en Sevilla
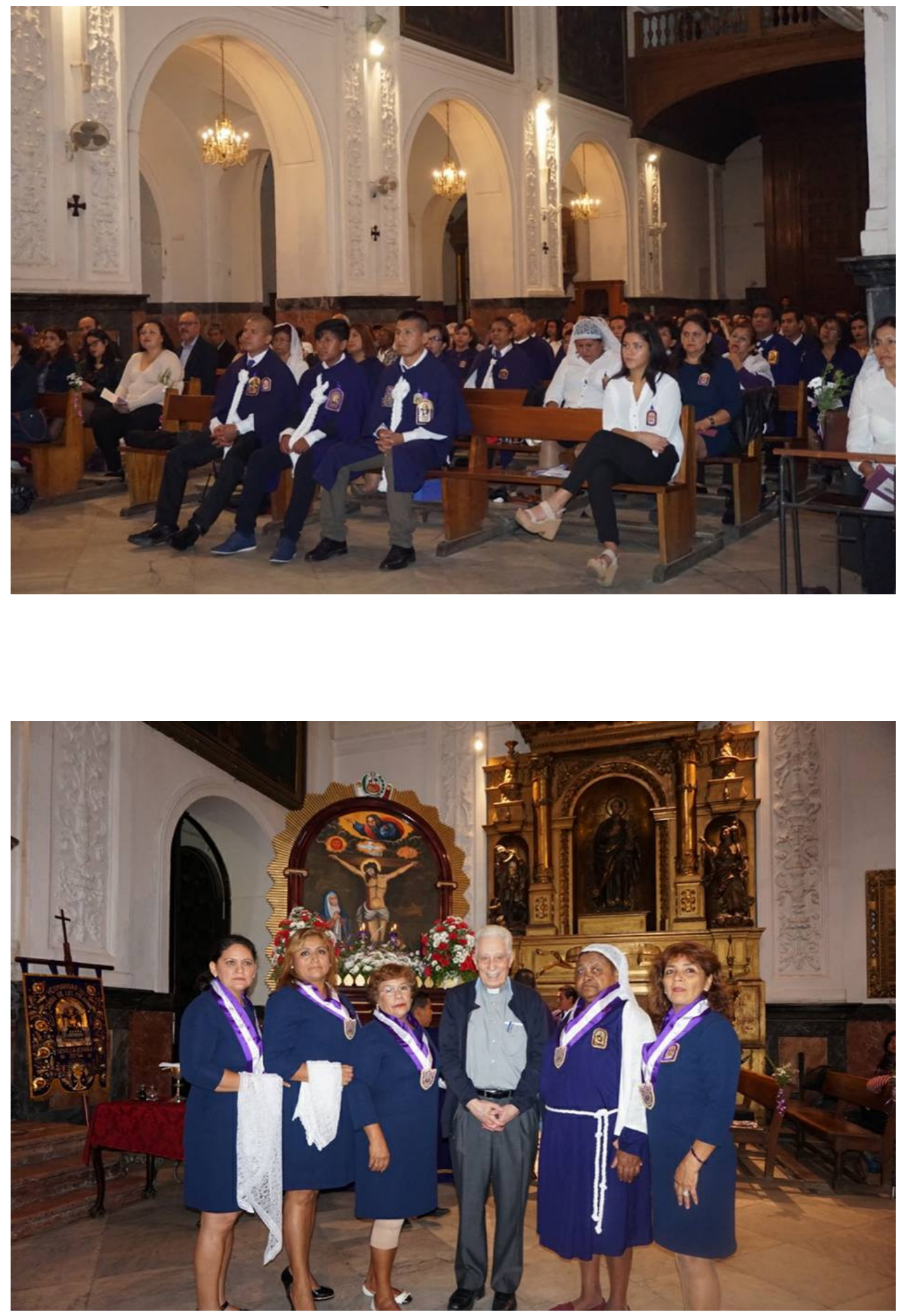
Cabe destacar que en estas misas también suele reservarse un lugar destacado a las autoridades del país de origen, representadas a través del cónsul y su familia. Éstos son acomodados en una segunda fila de bancos de la iglesia, justamente por detrás del grupo promotor de la romería. El papel que se reserva a este grupo es de gran interés, ya que de un lado se constata una voluntad por dotar a la fiesta de una imagen de oficialidad/ respetabilidad, pero por otro se aprecia un deseo por dejarles en un segundo plano frente al grupo de mujeres promotoras, que se colocan por delante de ellos en la iglesia y que asumen el verdadero protagonismo de la fiesta, disputándoles así el rol de representantes de la comunidad.

\subsection{La procesión}

Una vez culminada la eucaristía, la fiesta se reorganiza con vistas al traslado de la imagen sagrada al recinto preparado para la fiesta. En esta fase de la fiesta el Cristo o Virgen de referencia asume un protagonismo exclusivo, y se convierte en el eje sobre el cual va siendo construido el espacio de la fiesta. A lo largo del trayecto, todos los romeros seguirán respetuosamente a la imagen e intentarán, en la medida de lo posible, acercarse a ella para tocarla, mirarla de cerca y mostrar públicamente su veneración. Cuando la proximidad del recinto de destino lo permite, los romeros cargan con la imagen a pie, por turnos, formando una procesión que encabeza la imagen y en la que no faltan los cantos tradicionales y los vivas al patrón/patrona. Si la distancia del lugar lo impide, la procesión es practicada a la salida de la iglesia y a la entrada del recinto festivo, igualmente mediante el traslado a pie de la imagen rodeada de cantos y gritos de devoción.

\section{Imagen 5. Procesión de la Virgen de Caacupé por las calles de Sevilla}

\section{Fuente: Comisión organizadora Fiestas en honor a la Virgen de Caacupé en Sevilla}

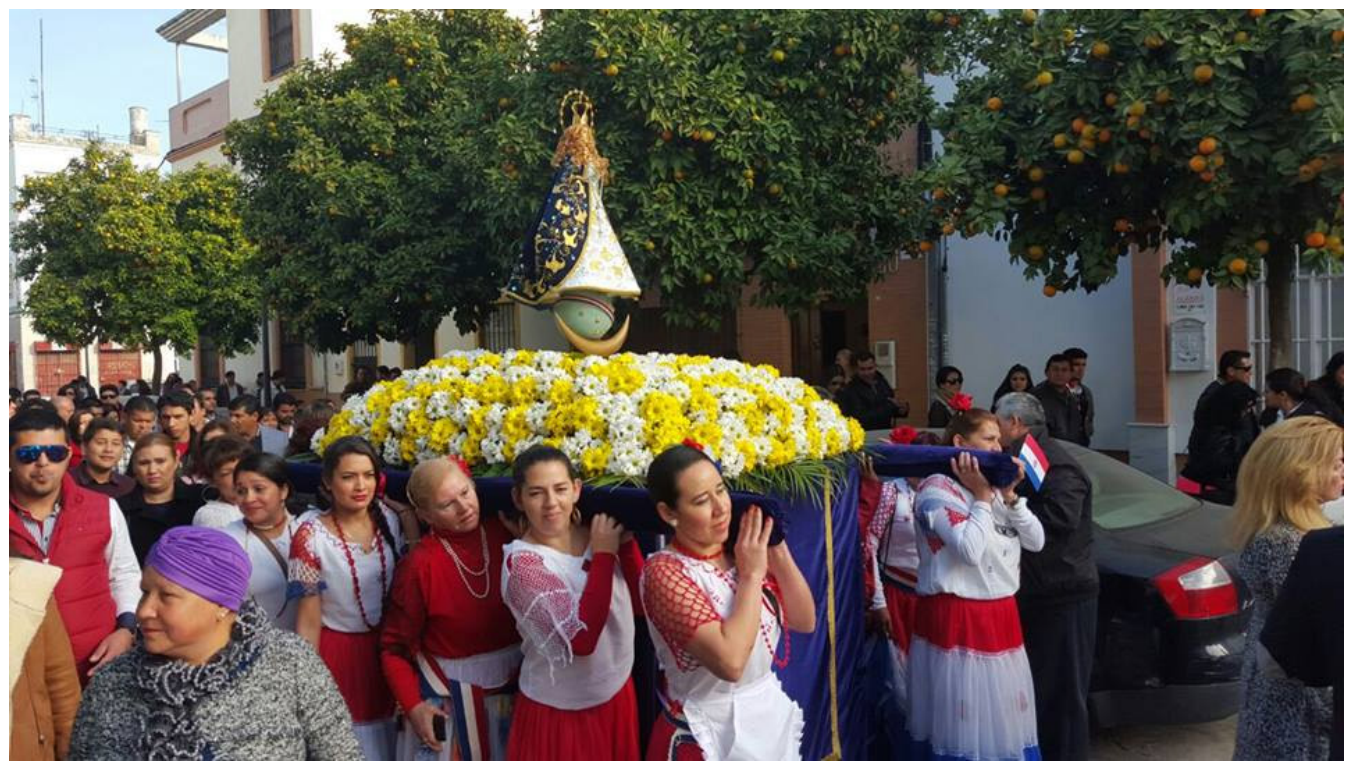


Debido a la dificultad que los inmigrantes encuentran cada año para dotar a la fiesta de espacios propios, y por tanto para reconstruir el trayecto de la procesión, ésta no cuenta con hitos fijos que marquen las paradas ni los momentos más emotivos del trayecto. Éstos son improvisados cada año en función del recorrido, siendo generalmente los mayordomos y sus ayudantes quienes van decidiendo en cada momento las paradas oportunas. En todo caso, los romeros intentan en la medida de lo posible revestir estas paradas de simbolismo y cargarlas de significado con discursos y cantos. Así sucedió, por ejemplo, en una romería del Señor de los Milagros que circunstancialmente atravesó en su recorrido uno de los puentes que cruzan el río Guadalquivir. Esta parada fue vivida con especial emotividad, no sólo por lo sugestivo del paisaje, sino también por el sentido que se le dio en los discursos de los promotores de la fiesta. Éstos subrayaron en clave poética el papel jugado por este río como origen de las primeras expediciones a América, y por extensión como arteria que comunica simbólicamente a la ciudad de Sevilla con el subcontinente latinoamericano y con su país de origen.

En otros casos las paradas de la procesión obedecen a la importancia que ciertos espacios tienen para la población inmigrante en concreto. Esto sucede cuando la procesión se detiene, por ejemplo, ante unas canchas deportivas o ante una plaza pública frecuentada por estos inmigrantes en su vida cotidiana. Igualmente las paradas pueden señalar la importancia que ciertos espacios tienen para el conjunto de la ciudad, como cuando la imagen se detiene ante la puerta del cementerio o ante el edificio del Rectorado de la universidad. Las paradas ejercen por tanto formas diferenciadas de demarcación del territorio, señalando en ocasiones espacios de especial importancia para un grupo étnico o nacional concreto, y en otros casos espacios locales cuyo reconocimiento afirma la pertenencia genérica de estos inmigrantes a la propia ciudad de Sevilla.

A lo largo de todo el recorrido los mayordomos y sus ayudantes visibilizan su protagonismo ocupando sistemáticamente los lugares más próximos a la imagen sagrada. Tocar a la imagen se convierte, durante el traslado, en la máxima distinción que uno de los miembros del grupo puede alcanzar. Por este mismo motivo, los propios mayordomos y sus ayudantes tratarán de monopolizar este privilegio en la medida de lo posible, y pondrán especial atención en evitar que determinados miembros del grupo ejerzan este honor de manera inmerecida. No es casual, en este sentido, que el fuerte protagonismo femenino en la organización de estas romerías se visibilice durante la procesión con la presencia preponderante de ellas en tanto cargadoras de la imagen. 
Imagen 6. Mujeres paraguayas cargan a la Virgen de Caacupé en Sevilla Fuente: Comisión organizadora Fiestas en honor a la Virgen de Caacupé en Sevilla

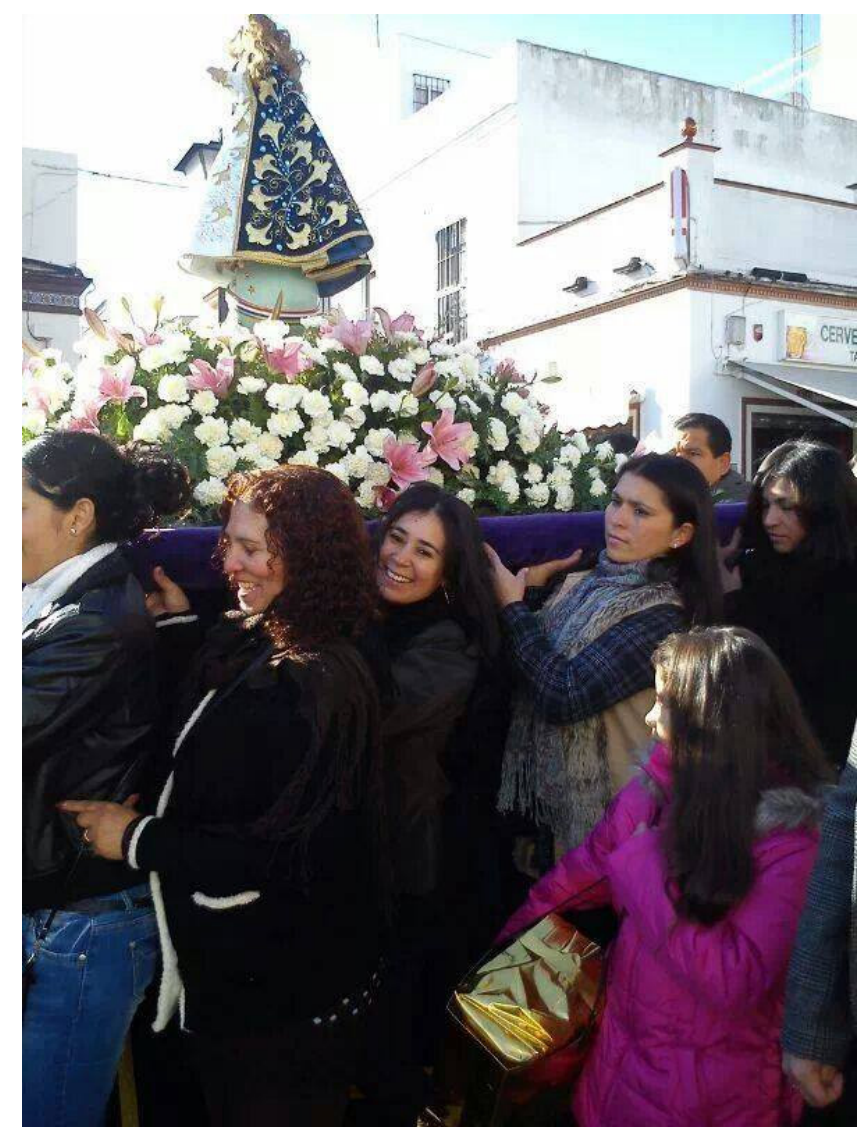

Imagen 7. Mujeres peruanas portan al Cristo de los Milagros en Sevilla

Fuente: Asociación religiosa de devotos del Señor de los Milagros en Sevilla

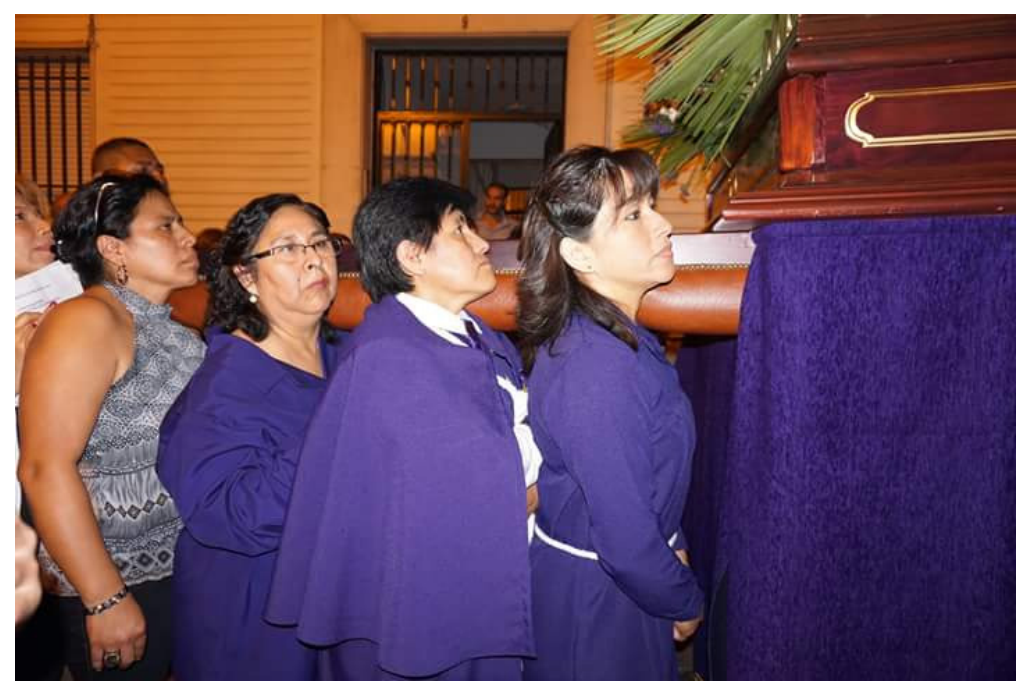


Cabe recordar en este punto el esfuerzo observado en estos promotores en cierta ocasión en que, debido a rencillas preexistentes, intentaban por todos los medios evitar que el cónsul y su familia cargasen la imagen. Comoquiera que la procesión resultó ser larga y los promotores acabaron cansados de cargarla, aprovecharon al máximo la presencia de un antropólogo local -a la sazón, quien escribe estas líneas- para "dignarle" con la carga de la imagen durante buena parte del recorrido. Con esta solución consiguieron que un sujeto ajeno al grupo -y por tanto inhabilitado para absorber el prestigio de cargar la imagen-facilitase el transporte físico de la imagen y de paso impidiese que el cónsul y su familia asumiesen tan preciado rol.

\subsection{La fiesta-convivencia}

Frente al carácter público de la iglesia y del recorrido de la procesión, la fiesta-convivencia es celebrada siempre dentro de un espacio construido como propio y exclusivo. El recinto de la fiesta está vetado de una forma más o menos explícita a todos aquellos que no son parte del grupo, y el formato de la fiesta está estrictamente orientado al consumo intragrupo. En este espacio tanto la decoración de las paredes como la comida, la música y los olores contribuyen a materializar una atmósfera que recrea las condiciones del país de origen y que afirma de manera rotunda los límites que separan a los miembros del grupo de quienes no lo son. Esta parte de la fiesta suele arrancar con un almuerzo que se prolonga invariablemente hasta altas horas de la madrugada. Se trata de la fase más prolongada de la fiesta, y aquélla que consigue aglutinar al mayor número de participantes.

La convivencia se desarrolla dentro de un formato ritual de comensalismo comunitario, donde al compartir la comida y la bebida se reafirma un sentimiento colectivo de pertenencia a un nosotros diferenciado. El grupo de origen es recreado en la forma de una comunidad de iguales ligados entre sí por lazos de afecto y cooperación. A lo largo de estas horas ser boliviano, ecuatoriano o paraguayo es afirmado como un motivo de orgullo y como la base de un vínculo de capital importancia.

Los asistentes participan colectivamente de una comida a base de platos típicos del país de origen, de modo que la propia gastronomía asume un papel importante como marcador de la identidad del grupo. Así, abunda el mole en las fiestas de Guadalupe, mientras que el ceviche subraya la ecuatorianeidad en la romería de la Virgen del Quinche y la peruanidad en la del Señor de los Milagros, acentuando para ello en cada caso los matices que distinguen la receta en cada uno de estos países. Igualmente la música servirá para marcar la especificidad del espacio de la fiesta, y será ajustada a las preferencias de cada grupo. No falta la interpretación de rancheras entre los mexicanos, mientras que los ecuatorianos adornan su fiesta con sanjuanitos y los peruanos lo hacen al ritmo de marineras. 
Imagen 8. Un grupo de mujeres prepara comida durante la fiesta en homenaje el Señor de los Milagros

Fuente: Asociación religiosa de devotos del Señor de los Milagros en Sevilla

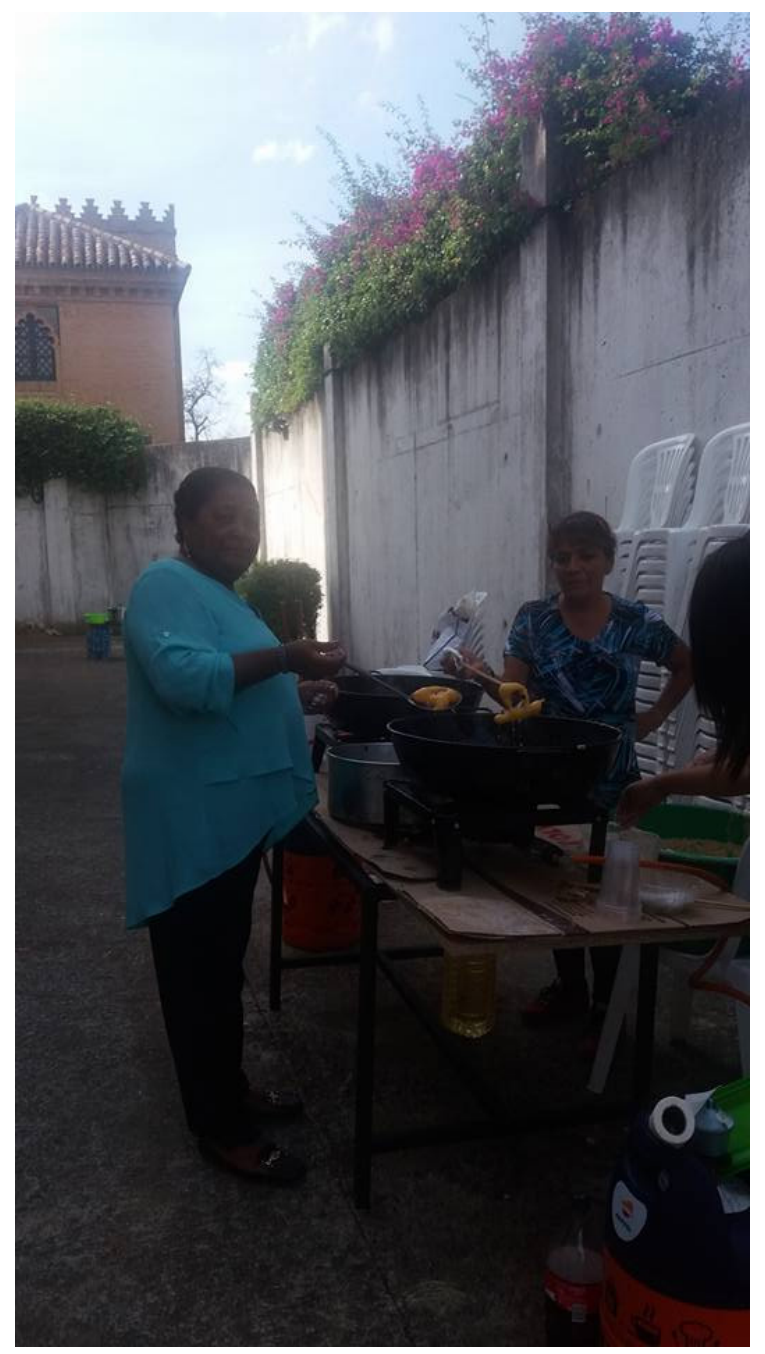

Estas convivencias romeras incluyen por lo general la actuación invitada de grupos folclóricos y artistas pertenecientes al grupo nacional protagonista. Los inmigrantes latinoamericanos, y muy especialmente los originarios de los países andinos, han conformado numerosos grupos amateurs de danzas folclóricas, varios de los cuales gozan ya de cierta reputación dentro de las comunidades migrantes, como el grupo Mayembe, el ballet Andalatinos o el grupo Mitimaes. Estas agrupaciones suelen asumir el protagonismo durante las horas de la tarde, interpretando varias actuaciones para los asistentes a la fiesta. Con el avance de la misma es común que se dé espacio a otros intérpretes aficionados a estilos musicales considerados no tradicionales pero igualmente identificativos de estos grupos, destacando los jóvenes cantantes y bailarinas de tecnocumbia y reggaeton. 
Imágenes 9 y 10. El grupo folklórico Mitiames representa danzas andinas durante la fiesta en homenaje a la Virgen del Quinche (Ecuador)

\section{Fuente: autor}
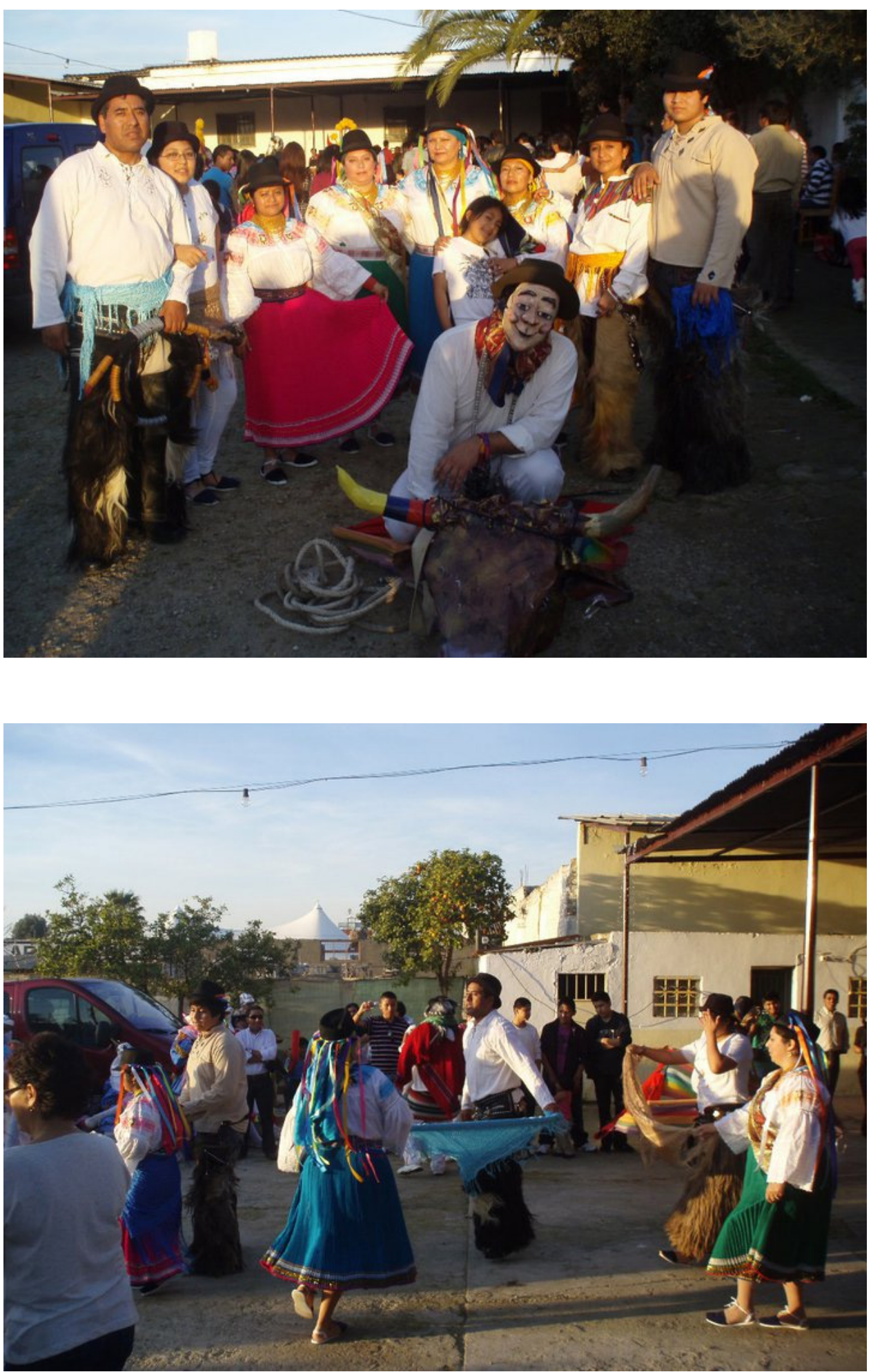
Estas actuaciones musicales ocuparán el espacio central de la fiesta, que siempre se encontrará presidido por la imagen sagrada. Tanto si el lugar de la celebración es una discoteca como si se trata de un edificio municipal o una finca rural, el Cristo o la Virgen serán dispuestos en un lugar visible para todos, y será en torno a ellos que irán discurriendo los acontecimientos centrales de la fiesta. El espacio ubicado junto a la imagen sagrada será ocupado por los mayordomos, que posarán a la vista de todos y que intervendrán en distintas ocasiones recibiendo el aplauso y el cariño de la colectividad. Con el transcurso de las horas, el perfil de los asistentes cambia, y va asumiendo un mayor protagonismo la población más joven, que se encarga de prolongar la fiesta hasta altas horas de la madrugada, a menudo dentro de un formato estandarizado de música, baile y consumo de alcohol.

\section{CONCLUSIONES}

Como se puede apreciar, el desarrollo de estas romerías moviliza una diversidad de referentes identitarios que permiten recrear la existencia de la comunidad y visibilizarla ante sí misma y ante los demás. La imagen de la comunidad no aparece con una forma fija y acabada, sino como una combinación cambiante de recursos estéticos y simbólicos. La romería evoluciona así en sus formas, pasando de consistir primero en la participación de una misa al acompañamiento posterior de la imagen en procesión, y finalmente su festejo mediante el baile, la comida y la bebida.

A lo largo de todo este proceso, los inmigrantes plantean formas diferenciadas de apropiación, delimitación y significación del espacio. En una primera fase estas formas apuntan la voluntad por participar de manera normalizada de los espacios compartidos con la población autóctona, representados en este caso por las parroquias locales. En la organización de la ceremonia religiosa se observa un interés activo por facilitar la asistencia de vecinos autóctonos, y especialmente por lograr la participación de representantes de la sociedad local como sacerdotes, responsables de ONGs locales y autoridades públicas. Posteriormente se visibiliza ante la sociedad receptora una práctica procesional que de un lado les identifica como grupo diferenciado y de otro enfatiza la proximidad estética con las fiestas religiosas autóctonas. Tanto el recorrido de las procesiones como sus paradas suelen ser estratégicamente planificadas en espacios públicos significados por su valor simbólico para el conjunto de los sevillanos. Si bien en esta fase el protagonismo recae ya de manera exclusiva en los promotores de la romería, inmigrantes en su totalidad, la figura del vecino autóctono está muy presente en esta fase en tanto espectador que debe ver y apreciar a un mismo tiempo la singularidad y la proximidad cultural que estas otras procesiones encarnan. Finalmente, la territorialización de esta fiesta también evoca, especialmente durante la fase de cierre, una voluntad por mantener los límites del grupo y su especificidad ante el resto de la sociedad. En esta convivencia final encontramos prácticas que se alejan considerablemente de la estética tradicional de la fiesta, y que 
incorporan ya marcadores de lo que en otros trabajos hemos apuntado como nuevos paisajes de la latinidad en Sevilla (Cuberos, 2014). Esta última fase se ubica siempre en espacios cerrados y generalmente periféricos, donde los asistentes son exclusivamente miembros del grupo nacional protagonista, o en todo caso de otros colectivos latinoamericanos, y donde no se prevé por tanto la presencia de vecinos autóctonos.

Todas estas formas de intervención sobre el territorio nos hablan, en definitiva, de una voluntad por participar de la ciudad sin renunciar por ello a la identidad propia. En este sentido, el proceso de re-territorialización de estas romerías permite visibilizar de un modo explícito la tensión que experimentan unos migrantes que necesitan simultáneamente ser parte de la sociedad en que viven sin abandonar por ello sus identidades culturales de origen. Las prácticas de apropiación, delimitación y definición del espacio público nos aportan una interesante fuente de datos en este punto. De un lado, la necesidad de reconstruir anualmente los referentes espaciales de la fiesta apunta a una cronificación de la precariedad en el acceso físico y simbólico a la ciudad. Ninguna de las romerías observadas ha logrado dotarse de referentes estables en Sevilla, y todas ellas continúan dependiendo cada año del favor personal de un párroco que se preste a oficiar una misa en un templo disponible, y de locales públicos o privados en que desarrollar la convivencia posterior. Ello provoca que, a diferencia de las romerías de los países de origen que pretenden evocar, estas fiestas carezcan en el contexto migratorio de un paisaje estable con referentes claramente reconocibles.

Se constata un interés por mantener la estructura formal de la fiesta fiel a los cánones considerados como tradicionales e identificados con el país de origen. No obstante, y de manera simultánea, la innovación es tolerada en base a los obstáculos materiales existentes, e incluso valorada positivamente cuando se interpreta que permite una aproximación estética a las procesiones autóctonas. Así, se ha observado ya la inclusión de bandas locales de cornetas y tambores en algunas de estas procesiones. Finalmente, el control del espacio romero permite a los impulsores del evento proyectar una visión compleja sobre sus vecinos, otorgándoles niveles desiguales de presencia en sus distintas fases: desde una ceremonia religiosa donde se busca la presencia autóctona a través de representantes destacados; hasta una fiesta final donde el vecino autóctono está ausente pero que sí se abre con frecuencia a una idea amplia de lo latino; pasando por una procesión donde es el grupo nacional quien asume en cada ocasión el protagonismo exclusivo y donde los autóctonos participan precariamente y en tanto espectadores.

De esta forma, la celebración de la romería permite a los inmigrantes latinoamericanos renegociar periódicamente el derecho a tener un lugar propio dentro de la ciudad. En un contexto de fuerte precariedad, donde la pertenencia a la sociedad receptora se construye siempre en términos desventajosos, estas fiestas permiten a los inmigrantes reafirmar su derecho a la diferencia procurando al mismo tiempo una sutil apertura hacia la 
sociedad receptora mediante la exposición pública de unas tradiciones percibidas como culturalmente cercanas a la población autóctona. En este sentido, podemos afirmar que el proceso de re-territorialización de estas romerías no consiste en un mero desplazamiento físico de su significado, sino en toda una reconstrucción del sentido de la fiesta. Si en el país de origen la romería evoca una imagen totalizadora de la comunidad dentro de un territorio construido como propio, en el contexto migratorio la comunidad es afirmada frente a una mayoría social de "otros", y se apropia estratégicamente de un territorio del cual se participa cotidianamente de un modo precario. El potencial de estas fiestas radica, en el nuevo contexto, en su capacidad para negociar el derecho a una identidad diferenciada en un entorno desventajoso. 


\section{REFERENCIAS BIBLIOGRÁFICAS}

Arbaci, Sonia (2008) "Hacia la construcción de un discurso sobre la inmigración en las ciudades del sur de Europa. La política urbanística y de vivienda como mecanismos estructurales de marginación étnica residencial". ACE. Arquitectura, Ciudad y Entorno 8(3), pp. 11-38.

Ares, Alberto (2011) "Iglesia como espacio transnacional. La religiosidad popular que viaja de Ecuador a España: la devoción a la Virgen del Quinche”. Migraciones 29, pp. 175192.

Barelli, Ana Inés (2014) "La Virgen de Caacupé como símbolo de paraguayidad en Bariloche, Argentina (1970-2012)”. Latinoamérica. Revista de Estudios Latinoamericanos 58, pp. 205-236.

Barth, Fredrik (1976) Los grupos étnicos y sus fronteras : la organización social de las diferencias culturales. México: Fondo de Cultura Económica.

Capel, Horacio (2002) "Las políticas de atención a las necesidades de los inmigrantes extranjeros de escasos recursos". Scripta Nova. Revista Electrónica de Geografía y Ciencias Sociales 117(6).

Castells, Manuel (1977) The Urban Question. London: Edgard Arnold.

Cuberos, Francisco José (2014) "Ser latinos en Sevilla. La articulación de una identidad panétnica en el contexto migratorio". Imagonautas: Revista Interdisciplinaria sobre Imaginarios Sociales 4(1), pp. 13-32.

De Certau, Michel (1984) The Practice of Everyday Life. Berkeley: University of California Press.

Garcés, Alejandro (2006) "Configuraciones espaciales de lo inmigrante: usos y apropiaciones de la ciudad”. Papeles del CEIC 20, pp. 1-34.

Gilroy, Paul (1994) The Black Atlantic: Modernity and Double Consciousness. Londres: Verso.

Harvey, David (1973) Social Justice and the City. Baltimore: John Hopkins University.

Jarrín, A.; Rodríguez, D. y De Lucas, J. (2012) "Los Centros de Internamiento para Extranjeros en España: una evaluación crítica”. Revista CIDOB d’afers internacionals 99, pp. 201-220.

Kong, Lily and Yeoh, Brenda S.A. (2003) The Politics of Landscapes in Singapore: Constructions of "nation". Syracuse: Syracuse University Press.

Lefebvre, Henry (1991) The Production of Space. Oxford: Blackwell.

Lojkine, Jean (1981) El marxismo, el Estado y la cuestión urbana. México DF: Siglo XXI. 
Martín, Emma (1992) La emigración andaluza en Cataluña. Sevilla: Fundación Blas Infante.

Martín, E.; Castaño, Á.; Sabuco, A. y Cuberos, F.J. (2008) El papel de las mujeres inmigrantes en el desarrollo e sus localidades de origen: el caso de las marroquíes y las ecuatorianas. Madrid: Ministerio de Igualdad.

Martín, E.; Cuberos, F.J. y Castellani, S. (2012) "Latin American Immigration to Spain". Cultural Studies 26, pp. 814-841.

Massey, D.S.; Arango, J.; Hugo, G.; Kouaouci, A.; Pellegrino, A. and Tylor, J.E. (1993) "Theories of International Migration: A Review and Appaisal". Population and Development Review 19 (3), pp. 431-466.

Massey, D.S.; Arango, J.; Hugo, G.; Kouaouci, A.; Pellegrino, A. and Tylor, J.E. (1998) Worlds in motion. Oxford: Clarendon Press.

Merino, Asunción (2003) "Relaciones entre gente, cultura y lugar en el fenómeno migratorio contemporáneo: los peruanos en España”. Revista de Indias 63(229), pp. 737 756.

Moreno, Isidoro(1974) Lashermandades andaluzas. Sevilla: Secretariado de Publicaciones de la Universidad de Sevilla.

Moreno, Isidoro (1990) "Rituales colectivos de religiosidad popular y reproducción de identidades de Andalucía”. En Josepa Cucó y Joan Josep Pujadas (eds.) Identidades colectivas. Etnicidad y sociabilidad en la Península Ibérica. Valencia: Generalitat Valenciana, pp. 269-284.

Moreno, Isidoro (1997) La antigua hermandad de los negros de Sevilla: etnicidad, poder y sociedad en 600 años de Historia. Sevilla: Universidad de Sevilla.

Odgers, Olga (2008) “Construcción del espacio y religión en la experiencia de la movilidad Los Santos Patronos como vínculos espaciales en la migración México/Estados Unidos”. Migraciones internacionales 4(3), pp. 5-26.

Piore, Michael J. (1979) Birds of passage. Migrant labor and industrial societies. Cambridge: Cambridge University Press.

Piore, Michael J. (1983) “El dualismo como respuesta al cambio y a la incertidumbre". En Luis Toharia (ed.) El mercado de trabajo: Teorías y aplicaciones. Madrid: Alianza, pp. 223-254.

Pujadas, Joan Josep (1990) "Identidad étnica y asociacionismo en los barrios periféricos de Tarragona”. En Josepa Cucó y Joan Josep Pujadas (eds.) Identidades colectivas. Etnicidad y sociabilidad en la Península Ibérica. Valencia: Generalitat Valenciana, pp. 307-323. 
Sassone, Susana María (2007) "Migración, territorio e identidad cultural. Construcción de "lugares bolivianos" en la ciudad de Buenos Aires". Población de Buenos Aires 4(6), pp. 9-28.

Torres, Francisco (2006) “La inserción urbana de los inmigrantes y su participación en la ciudad”. En Carles Simó y Francisco Torres (eds.) La participación de los inmigrantes en el ámbito local. Valencia: Tirant lo Blanch, pp. 91-131.

Weber, Max (1988) El político y el científico. Madrid: Alianza Editorial.

Winchester, H.P.M.; Kong, L. and Dunn, K. (2003) Landscapes: Ways of Imagining the World. Harlow: Pearson Prentice Hall. 